\title{
CONSIDERACIONES INTERPRETATIVAS SOBRE EL AMOR DENTRO DEL MUNDO SOCIAL
}

\section{INTERPRETIVE CONSIDERATIONS ON LOVE WITHIN THE SOCIAL WORLD}

\author{
Nathalie Forero Perdomo ${ }^{1 *}$ \\ naforerope@unal.edu.co \\ ${ }^{1}$ Universidad Nacional de Colombia, Bogotá, Colombia \\ *Correspondencia: Nathalie Forero Perdomo. Email: naforerope@unal.edu.co
}

Recibido: 03.08.21 | Aprobado: 21.08.21

\section{RESUMEN}

El objetivo de esta investigación es ofrecer consideraciones interpretativas para la comprensión del concepto de amor dentro del mundo social. El texto aborda el amor desde una dimensión histórica que atraviesa la concepción griega clásica, pasando por el acercamiento al amor cristiano y sus elementos constitutivos, hasta plantear ideas del amor heteropatriarcal y la perspectiva feminista del amor como propuesta crítica emancipatoria y de transformación del orden social. Esta investigación inicia con la relación entre emoción y razón con un ejemplo del estrecho vínculo entre el individuo y su comunidad en la construcción de valores, hábitos y códigos simbólicos que integran de forma armoniosa la emoción y la razón en la construcción tanto individual como colectiva de los sentimientos y los afectos. A continuación, se presenta el amor como concepto de análisis de las Ciencias Sociales en los aportes de distintas disciplinas que han posibilitado el interés del amor como temática social. Finalmente, se presenta la trayectoria histórica del amor como concepto desde la Grecia Clásica hasta visiones contemporáneas acerca del amor tradicional de corte patriarcal y puntos de vista críticos sobre el amor como dominación y poder en sus posibilidades de cambio como idea del amor como construcción social e histórica.

Palabras clave: Amor, dimensión histórica, emoción, razón.

\begin{abstract}
The aim of this research is to offer interpretative considerations for the understanding of the concept of love within the social world. The text addresses love from a historical dimension that crosses the classical Greek conception, passing through the approach to Christian love and its constitutive elements, to put forward ideas of heteropatriarchal love and the feminist perspective of love as a critical emancipatory and transformative proposal of the social order. This research begins with the relationship between emotion and reason with an example of the close link between the individual and his community in the construction of values, habits and symbolic codes that harmoniously integrate emotion and reason in the individual and collective construction of feelings and affections. Next, love is presented as a concept of analysis of the Social Sciences in the contributions of different disciplines that have enabled the interest of love as a social topic. Finally, the historical trajectory of love is presented as a concept from Classical Greece to contemporary visions of traditional patriarchal love and critical views on love as domination and power in its possibilities of change as the idea of love as a social and historical construction.
\end{abstract}

Keywords: Emotion, historical dimension, love, reason. 


\section{LAS EMOCIONES}

Las emociones son un impulso primitivo que ha facilitado la supervivencia de la especie humana y ha traído implícito en su desenvolvimiento, la manifestación de una acción. La palabra emoción proviene del latín movere y el prefijo 'e-', que significa "moverse hacia" (Goleman, 2010, p. 14) por lo cual, en el largo proceso de evolución humana, las emociones son un mecanismo sofisticado de regulación de la vida (Damasio, 2000, p. 71) y han jugado un papel muy importante en su supervivencia.

Este móvil biológico y adaptativo de las emociones humanas es posible en la medida en que existe una correspondencia entre las estructuras sociales y las afectivas como requisito indispensable del funcionamiento continuado de la sociedad (Torregrosa, 1984, p. 187; Bolaños, 2016, p.181), es decir, las emociones se construyen colectivamente, en un complejo entramado social que "le señala al individuo lo que debe sentir y cómo debe sentir" (Bolaños, 2016, p. 186) configurando, de este modo, la gestión de los afectos y la forma de ser en sociedad.

El repertorio emocional ha comenzado a ser tenido en cuenta, recientemente, en el campo disciplinario de las Ciencias Sociales, para entender cómo se enlaza el ámbito emocional con el racional en el ser humano. Esa coexistencia individual de emoción y razón contiene los distintos modos de respuesta ante diversas situaciones de la vida que, en cierta medida, interactúan en los seres humanos, así pues, "la mente emocional y la mente racional constituyen, como veremos, dos facultades relativamente independientes que reflejan el funcionamiento de circuitos cerebrales distintos, aunque interrelacionados." (Goleman, 2010, p. 17) lo cual, permite inferir cómo el ser humano ha reaccionado a situaciones externas desde su evolución hasta la actualidad.

En este sentido, la música y las emociones están vinculadas estrechamente, tanto en el individuo como en la comunidad, pues, el oyente elabora esas emociones, a través de la música, de acuerdo con su historia personal que está conectada también a valores y parámetros de su propia comunidad. De esta forma, la emoción, despertada a partir de la música, surge como un tipo de comprensión de la realidad circundante.

Así lo explica María Soledad Cabrelles Sagredo:

Se deben considerar el elemento subjetivo de cada oyente, su historia personal y su estado de ánimo en el momento de la escucha, que hace que la música sea en sí misma un símbolo inacabado que permite que cada persona proyecte en ella sus anhelos, conflictos, carencias, recuerdos, tristezas y alegrías. (2007, párr. 67)

De esta forma, comprender el vínculo entre la emoción y la razón es crucial para avanzar en la interlocución entre el lenguaje musical y las emociones que construyen memoria colectiva y fortalecen las relaciones sociales, así como elabora una imagen de sociedad en la que su música se crea y se disfruta, porque recurre a elementos propios de costumbres, valores y códigos simbólicos que se fijan en los afectos individuales en relación con el entorno social y el imaginario colectivo.

A propósito, es necesario recalcar acerca de la relación entre emoción y pensamiento en el que estos: 
Se hallan inexorablemente unidos y, en consecuencia, albergamos sentimientos sobre todo lo que hacemos, pensamos, imaginamos o recordamos. El viejo paradigma que proponía un ideal de razón liberado de los impulsos de la emoción se ha sustituido por el de armonizar ambas funciones integrándolas en el concepto de inteligencia. (Cabrelles, 2007, párr. 46).

Por esto, la relación que los oyentes hacen de la música promueve el arraigo propio relativo a los recuerdos y las emociones que despierta la música y la conexión vital e identitaria del individuo con su comunidad.

De tal manera, Javier García Liendo en "Las chicherías conducen al coliseo: José María Arguedas, tecnología y música popular", se remite a José María Arguedas quien utiliza el río como vehículo de tradiciones y de sonidos. Dice García: “el río compone la música de la cultura y la arrastra en su recorrido. En la medida en que la música se extiende por el cosmos deviene un espacio que unifica culturalmente a la gente que vive en poblados lejanos" (2012, p. 152), y resalta aquellos espacios de sociabilidad que son las chicherías - más provinciales-y los coliseos - más cosmopolitas- donde se dan encuentro las culturas para intercambiar, nutrirse e irse construyendo.

La música, desde esta perspectiva, es importante en la construcción de los afectos ya que cala en muchos espacios del mundo social. En este sentido, García enfatiza:

En la descripción de Arguedas, la música del río está compuesta de los sonidos de la naturaleza y el mundo social, y está presente en ambos mundos: en los bosques y las aves, en los maizales, los riachuelos y la vida humana: 'y está en el corazón de los hombres que viven en la quebrada, en su cerebro, en su memoria, en su amor y en su llanto’ (Arguedas ctd en García, 2012, p. 152)

De este modo, la emoción a través de la música permite conmover desde aquellos elementos como constructo cultural, ya que inspira a la creación artística por medio del intercambio musical entre culturas y diversos universos simbólicos y que se nutre en colectividad.

\section{SENTIMIENTO POPULAR COMO DATO SOCIAL}

En Psicología social del Japón moderno el sociólogo Munesuke Mita realiza un análisis sobre las emociones japonesas a través de 451 canciones populares (1996, p. 89) como datos de psicología social. En ellas descubre múltiples factores emocionales como: ira, resentimiento, desesperación, autodesprecio, etc; factores que le servirán a Mita para determinar los motivos o elementos temáticos más comunes de aquellas canciones populares del Japón.

Esta perspectiva de psicología social en las canciones populares japonesas es útil para abordar el tema del amor. En este sentido, las canciones populares recurren a generalizaciones o a universalizaciones de sentimientos individuales, y por ello, aquel sentir personal es común a todos, como es, en este caso el amor, un vínculo de afecto con otras personas, con las costumbres de infancia o con el propio territorio y la sociedad.

Mita añade en su trabajo que, la universalización de esos sentimientos se expresa en la canción popular "de forma concreta y figurada en una situación típica o un personaje 
típico" (p. 100) cercano al universo simbólico de las partes individuales de la comunidad, y los hace responder con simpatía a esa generalización como un sentimiento "respaldado por millones de experiencias individuales" (p. 100) haciendo profundamente provechosa la música popular para la construcción colectiva de los afectos y las emociones en la construcción de identidad.

En consecuencia, la canción popular logra tener un profundo impacto en la sociedad de donde proviene, porque se cuela en los espacios hogareños, se disfruta en los carnavales y es esa participación, la que le da una relevante ventaja comparativa a la canción popular sobre otras expresiones populares, ya que:

estas canciones no sólo se reciben con agrado por la masa, sino que llegan a tener el calificativo de populares cuando las masas de la época las cantan en voz baja (o en voz alta o al unísono) por su propia iniciativa, o sea, con la participación activa de las masas mismas. (Mita, 1996, p. 34)

Esa pervivencia de la canción popular cuando es aceptada e incorporada a la cultura, puede decirse que se arraiga en la identidad de su comunidad. Entonces, estas canciones son más que comerciales pues apelan a emociones y sentimientos con los que los individuos se identifican, estrechamente, en un contexto específico y al interior de su comunidad. Su éxito significa mucho más que un aspecto netamente mercantil porque apela al sentimiento prístino de la comunidad en una época determinada.

\section{EL AMOR COMO CONCEPTO DE ANÁLISIS SOCIAL}

El amor, como idea y sentimiento universal, constituye una preocupación reciente dentro del área de conocimiento de las Ciencias Sociales. Así, lo explican Adriana García y Priscila Cedillo en Tras los pasos del amor (2009) donde rescata el interés multidisciplinar sobre el tema de los afectos y el amor como sentimientos humanos, a partir del aporte que esta perspectiva supone desde su dimensión histórica.

El amor ha sido un campo disciplinario apenas problematizado en la transición de los siglos XIX y el XX, siendo relegado de las Ciencias Sociales por considerarse pre social. Afortunadamente este concepto, ha empezado a comprenderse como una discusión en el campo de las emociones y los sentimientos.

Según García y Cedillo, el amor ha sido tema de interés interdisciplinario para la filosofía, la sociología, la psicología, los estudios culturales/ género/ sexualidad, la Historia y por supuesto, para la literatura (2009, p. 577) aludiendo a que, aunque esta demarcación disciplinar continúa, en tanto que disciplinas específicas, es posible decir que préstamos, intercambios y adscripciones disciplinares, a propósito del amor como temática social, se han incrementado, añadiendo que la biología ha sido una fuente importante para su conceptualización en los hallazgos de las Ciencias Sociales (p. 590).

Recientemente, desde mediados del siglo XX, las Ciencias Sociales han vuelto los ojos, con gran interés sobre el tema del amor adscrito al tema de las emociones y sentimientos humanos siendo, puntualmente, contemplado en la historia de la familia y la vida privada, desde una perspectiva, esencialmente, doméstica. 
Un espectro más general, que centró su análisis en el tema del comportamiento emocional, ha sido la investigación del sociólogo Norbert Elias en "su análisis del proceso civilizatorio y su relación con el control de los afectos" (p. 560); Elias "muestra la autocontención de los afectos como un aspecto fundamental de las formas de control social que sostienen la sociedad cortesana y la institución del Estado absolutista entre los siglos XVI y XVIII en Francia y Alemania" (Bolaños, 2016, p. 181). A partir del siglo XXI, se desarrolló toda una corriente sobre el tema del amor en la sociología norteamericana.

Concluyen García y Cedillo que, la conceptualización del amor ha tenido un giro contundente en las investigaciones con perspectiva feminista en el orden de amor y sexualidad, desde los años setenta del siglo pasado. Estas investigaciones descubrieron en el amor y en la sexualidad, formas concretas de dominación hacia la mujer (p. 561) e impulsaron novedosas investigaciones, que han tomado, de manera transversal, el acercamiento al discurso sobre sentimientos y emociones, ofreciendo una perspectiva desde el amor y el cuidado, como emancipación.

La perspectiva feminista sobre el amor ha cuestionado las dinámicas tradicionales de la familia y las relaciones interpersonales en las que está en juego sexualidad, afectividad, costumbres, formas de control, abuso de poder y dominación, sustentados principalmente por el sistema patriarcal que insiste en "mantener la sumisión de las mujeres y el gran engaño de la superioridad masculina" (Esperanza Bosch, Victoria A. Ferrer, Virginia Ferreiro y Capilla Navarro, 2013, p. 13). En este enfoque feminista, el amor supera la visión pre - cultural de las emociones y es analizado "como un elemento clave de un entramado heteropatriarcal mucho más complejo" (Saiz, 2013, p. 11) que, como construcción social es susceptible de transformarse y cuestionar el amor patriarcal para construir nuevas formas de orden social que desmonten la subordinación de las mujeres.

Desde el feminismo el amor está anclado a la Historia y a dinámicas tradicionales de poder. Al respecto, Marcela Lagarde dice:

En la concepción tradicional del amor, el amor es funcional a la concepción tradicional del poder. Que poder y amor estén vinculados quiere decir que el amor es una fuente de poder, que muchos mecanismos amorosos permiten acumular poder, que al amar y al ser amados ganamos poder, que al no amar y al no ser amados perdemos poder. $\mathrm{Y}$ quiere decir que la experiencia amorosa es también una experiencia política. Porque el amor reproduce formas de poder. Y porque el amor es también un espacio para la liberación y la emancipación políticas.” (2001, p. 20)

En este sentido, propuestas muy recientes como la de Manuela D' Ávila considera que deben revertirse los estándares sociales y de belleza: "No ser prisionera de estándares únicos de belleza que se estructuran de manera racista (siempre blancos) y son absolutamente gordofóbicos y heteronormativos.” (D’ Ávila, 2020, p. 30) estándares desde donde sistemáticamente, pervive la opresión y dominación de la mujer.

D' Ávila apuesta por "la búsqueda de la libertad para la humanidad, la búsqueda de su emancipación” (p. 31). Este enfoque es un giro novedoso y necesario, desde el cual, la 
perspectiva del amor incluye a la humanidad entera desde el cuidado y la libertad, sin distinciones maniqueas entre hombres y mujeres. Estas propuestas apuestan por el amor como construcción social y en su dimensión histórica susceptible de ser transformado.

\section{DIMENSIÓN HISTÓRICA DEL AMOR}

Comprender que el amor tiene raíces históricas hace necesario remitirse a su desarrollo desde la antigüedad griega. Ubicarse en lo planteado en El Banquete de Platón como uno de los pivotes sobre los que se construye la problematización Occidental de la concepción de la idea de amor. Allí, los griegos se congregan para improvisar un discurso en elogio del Amor.

Phaidros comienza su elogio diciendo que el Amor es el dios más antiguo de todos y de ellos, el que más beneficios otorga a los hombres (Platón, 370 A.C/2019, p. 10), así, el Amor es "el más apto para hacer virtuoso y feliz al hombre durante su vida y después de la muerte." (p. 12). Seguidamente, Pausanias desglosa al Amor en dos clases que se deben considerar, y ya que la existencia del amor admite una Venus celestial y otra popular, hay que saber cuál de los dos tipos de Amor sería más plausible elogiar. Pausanias concluye que es elogiable el amor celestial que se fascina por el alma bella y virtuosa.

El elogio del Amor por parte de Eryximacos inicia desde su conocimiento médico. Luego, interviene Aristófanes refiriéndose a la naturaleza del hombre concluyendo que a causa de la insolencia de la especie andrógina recibió de los dioses la división de su cuerpo esférico y tuvo que erguirse sobre dos piernas. En aquella búsqueda por encontrar la otra mitad y por pedir benevolencia de los dioses y evitar su castigo, se comprendería la idea del amor, pues al encontrar su otra mitad, se hallaría la felicidad de la naturaleza primitiva de unidad (p. 23) es decir, el amor como completitud.

Seguidamente, viene el elogio del amor por parte de Agatón para quien el amor es paz, amistad, eternidad, delicadeza, juventud y belleza. Es quien domina el placer y las pasiones, en tanto que es la mayor temperancia (p. 26) además, es la reunión de todo lo bueno, lo bello y el lazo de unión de toda una sociedad (p. 27).

Este elogio del amor sirve de enlace para el último discurso sobre el amor a cargo de Sócrates. En su elogio, se refiere a que este es deseo de lo bueno y de lo que nos hace felices (p. 34), es deseo y posesión de bondad y esa búsqueda de bondad va tomando el nombre de amor. Dicha búsqueda es la generación y producción en la belleza, como la unión del hombre y la mujer es obra divina; unión en la cual lo mortal se inmortaliza, a partir de producir en la belleza y en la fecundidad.

Al final Sócrates concluye que el amor "descubrirá de repente una maravillosa belleza (...) belleza eterna, increada, imperecedera, exenta de incremento y de disminución" (p. 39), por lo tanto, el amor socrático es la búsqueda de la bondad y de la belleza absolutas.

Esta concepción hace parte del paradigma idealista al que hace referencia Irving Singer para el cual, Platón, Aristóteles y Plotino tienen un enfoque idealista del amor (1999a, p. 82), esto es, como idea y modelo y en el que se reconocía la búsqueda de algo superior a la materia. 
Siglos más tarde, en oposición a esta concepción idealista griega, los poetas latinos Ovidio y Lucrecio entendieron el amor en su dimensión fisiológica y natural a las leyes mecánicas. Ellos no idealizaron el amor en su trascendencia mística sino en su corporeidad (p.104); Ovidio idealiza el deseo sexual y la satisfacción de los instintos, mientras Lucrecio "idealiza el hecho universal de la energía pulsional, como si en realidad nada más importara en la naturaleza" (p. 167) poniendo el énfasis en la fertilidad, su naturalismo enaltece a Venus como categoría biológica de preservación humana.

Sobre estas concepciones se fueron edificando nuevos enfoques sobre el amor. Uno de ellos fue el amor religioso cristiano que tenía en cuenta cuatro elementos importantes acerca del amor en el mundo cristiano, estos elementos fueron: eros, filia, nomos y ágape (p. 190).

Esta relación de conceptos es necesaria para comprender los orígenes del amor cristiano y para un análisis comprensivo de la idea de amor en su conjunto y de qué manera esta idea abarca la naturaleza, el origen, el compañerismo en comunidad, la abundancia y la generosidad sin medida.

Irving Singer presenta los elementos del amor cristiano, a partir de dos cosmologías distintas: una griega y otra judía. Así, eros, de origen griego, apelaba al conocimiento, el cual se traducía, como se ha dicho, en la búsqueda de la Belleza absoluta y la suprema Bondad.

El primer nuevo enfoque sobre el amor en el medioevo tuvo que ver con que el amor cristiano interpretó que el eros platónico, de naturaleza trascendente, iba en busca de bondad y belleza divinas, es decir de Dios. La mística cristiana lo adaptó de acuerdo con la conjunción espiritual: "Allí donde el amante platónico alcanza el Bien poseyéndolo mediante el conocimiento de la realidad, el místico va en pos de una conjunción de los espíritus, un sentimiento de comunión entre dos personalidades” (p. 205), refiriéndose a la unión conyugal, en términos de sacramento cristiano, ya que la explicación de la unión entre dos personas corresponde más al sentimiento que a la razón.

El segundo elemento fue la filia cristiana, la cual se nutrió de la idea aristotélica de la amistad perfecta, entendida como "la fraternidad entre los hombres, la comunidad de los creyentes, el vínculo entre Cristo y su iglesia, entre Dios y el alma humana, en último término, entre las personas de la Santísima Trinidad" (p. 190), en el sentido en que, el amor une a los hombres y les otorga un valor especial dentro de dicha comunidad; un lugar donde los cristianos pudieran tener acceso a Dios en una relación entre lo humano y lo divino. Prueba de amistad perfecta, era aquella comunidad de hombres que tuvieran algo en común y estuvieran en armonía unos con otros, en suma, era la fraternidad como idea de familia.

En este sentido, el cristianismo sometió a revisión estos conceptos griegos de acuerdo con las necesidades del dogma (p. 210), así que la filia de Aristóteles se entendió como la hermandad entre los hombres a partir de dos ideas. Primero, la sagrada familia: Jesús, María y José y segundo, la sociedad como fraternidad que emanaba de la Santísima Trinidad. Una idea demasiado abstracta, pero, que permitió hacer cognoscible la experiencia cristiana en la tierra. 
El nomos como tercer elemento del amor cristiano, tuvo que ver con el arraigo propio de los orígenes no elegidos, pero a los que se les otorga gran valor, esta idea se entiende como compasión nativa: "El sentimiento de piedad tiene valores objetivos que los judíos, como los seguidores de Confucio, estuvieron prestos a reconocer. Lo mismo que los antiguos chinos, los hebreos se dieron cuenta de que no hay hombre que consiga su integridad interior si niega sus orígenes" (p. 284), como una manera de que los cristianos afrontaran su presente y su futuro en relación con su propio pasado y con la fidelidad a sus propios orígenes.

El cuarto y último elemento que la idea del amor cristiano sustrajo del pensamiento judío fue el ágape, como amor incondicional y generoso en su superabundante bondad. Esta bondad tuvo que ver con el amor de Dios hacia los hombres. Dios ama y "lo hace porque disfruta de ser generoso, está en su naturaleza y de todas maneras, es obvio que sus recursos son interminables (...) al ser indiscriminado, el amor de Dios ha de ser uniforme, así como gratuito e inmotivado” (p. 322), el ágape es propio y únicamente lo ofrece Dios a los hombres, es el elemento que, para el mundo cristiano, hace que Amor se equipare a Dios.

Hacer la distinción entre el ágape, proveniente de Dios, y el amor en el mundo terrenal, hizo posible comprender la filosofía del amor humano en la Edad Media en la figura arquetípica de los trovadores del siglo XII, quienes le cantaban al amor idealizado en las relaciones entre dama, caballero y trovador.

Esta nueva filosofía del amor humano terrenal fue desaprobada por las concepciones cristianas sobre el amor; "Cuando la tradición septentrional del amor cortesano complementó el neoplatonismo de los trovadores con las ideas de Ovidio sobre el adulterio y la libertad sexual, el peligro que corrió la doctrina eclesiástica fue obvio" (p. 416), puso una clara distancia entre la ciudad de dios, su amor religioso y la ciudad de los hombres y su amor cortesano durante toda la Edad Media.

Este amor cortesano de los siglos XII y XIII nació del trovador - poeta más como género literario y manual de comportamiento caballeresco, que como inspiración religiosa. El amor cortés fue la estilización del mundo de las cortes medievales y de una pedagogía de la contención, por eso mismo, su intención fue la de regular los apetitos masculinos desenfrenados.

En este sentido, se puede decir que la canción trovadoresca se inspiró en dar sentido al amor sin esperanza, a aquel amor completamente desgraciado:

La lírica provenzal, está dominada por este tema: el amor, pero no el amor feliz, colmado o satisfecho sino, al contrario, el amor perpetuamente insatisfecho en el cual no hay más que dos protagonistas: el poeta que repite una infinidad de veces su lamento y una bella dama que siempre le dice que no. (Rougemont ctd en Dufour, 1999, p. 210)

Esta dama que inspira la canción trovadoresca y en este sentido, el amor cortesano, encarnaba la belleza idílica y las virtudes de una imagen muchas veces ficticia. De esta manera, el trovador no tenía que referirse a una mujer determinada. 
La lírica trovadoresca se nutrió de la pedagogía del control de los impulsos caballerescos, así como también del ideal de la vida bella. Por lo tanto, los trovadores cantaban "a la mujer amada de la misma forma, la dotan de las mismas gracias y la representan como encarnación de las mismas virtudes e idéntica belleza" (Hauser, 2012, p. 61); así, el mundo cortesano aspiraba a la vida bella tanto en lo ceremonioso de su estilo y de su vida heroica caballeresca, cuanto más que en comprender que la belleza residía en el amor:

Es de esta forma una exigencia social [aspirar a la vida bella], una necesidad tanto más imperiosa cuanto más feroces resultan las costumbres (...) La violencia desbordante de la pasión lo exige. Si las emociones no se dejan enmarcar en las formas y en las reglas, es la barbarie. La Iglesia tenía la tarea de reprimir la brutalidad y lo licencioso del pueblo, pero no era suficiente. La aristocracia, por fuera de los preceptos de la religión, disponía de una cultura propia, la cortesía, que marcaba las normas de su conducta (...) En la realidad, la vida sexual de las clases altas continuaba siendo de una rudeza sorprendente. (Huizinga, 2012, p. 427)

La canción trovadoresca, como la propia vida cortesana, resultaba ser una "poesía de sociedad" en la que la experiencia real se escondía en las formas de la cortesía (Hauser, 2012, p. 61), en el que la vida cortés era parte de un juego masculino (Duby, 2012, p. 13) regulado por la mesura y la amistad y el control de sus pasiones "las más turbulentas, las caldeadas por las pulsiones de la carne" (p. 26), convirtiendo dicha regulación en el cambio de la salvaje vida medieval por la revolución psíquica del siglo XII (Dufour, 1999, p. 207), que en cierta medida, modificó la concepción del amor, como es el caso del amor cortesano.

Esa revolución psíquica comenzó cuando la Edad Media reunió en la palabra amor tanto, los placeres de la carne como la afección de los amigos, el vínculo feudal entre señor y vasallo, y la caridad cristiana (Burnley, 2012, p. 222), en este sentido, lo que se conoció en la vida cortesana como fine amor fue sinónimo de un sentimiento perfecto, excelente, inagotable y puro. Aunque, también fue considerado como intensificador del sentimiento de deseo y concupiscencia.

La amplitud y lo abstracto de este término se empleó como representación de "la excelencia en el amor valuado en términos de la teoría psicológica medieval” (p. 232) y de la idealización que hace parte del fine amor emparentándose con el amor platónico y el religioso, en el sentido en que la idealización femenina, ya fuera ficticia o real, en la que el trovador se inspiraba, era de una gran perfección y abundante en modales, moralidad y prestancia social.

Así, los trovadores cantaban a aquella dama cuya "excelencia inherente de toda su personalidad que despierta su amor, natural e inevitablemente como un imán atrae hacia sí a un objeto de hierro" (Singer, 1999b, p. 67), musa de la que brota amor, deseo, prestigio, belleza y por supuesto, inagotable bondad.

Luego, el Humanismo renacentista se ocupó en recuperar las ideas sobre el amor que habían quedado en la filosofía griega y el mundo cristiano. Es así como el italiano Marsilio Ficino retomó las ideas de Platón y en su "De Amore. Comentario a «El 
Banquete» de Platón” y, en este comentario, reinterpreta la noción de amor como deseo de belleza que existe en la armonía de todas las cosas. Dice Ficino:

Cuando decimos amor, entended deseo de belleza. Porque ésta es la definición del amor en todos los filósofos. La belleza es una cierta gracia, que principalmente y la mayoría de las veces nace en la armonía del mayor número de cosas. Y ésta es triple. Porque la gracia que hay en los espíritus, lo es por la consonancia de muchas virtudes. La que hay en los cuerpos, nace de la concordancia de líneas y colores. Y del mismo modo la gracia altísima que hay en los sonidos, viene de la consonancia de muchas voces. (2001, p. 30)

De esta manera, esta concepción acerca del amor se manifiesta en Dios que está en todas las cosas; en el alma, en la naturaleza y en la corporeidad humana. Reafirmando el amor ligado a la belleza y la bondad, además de estar presente en todas las formas y en los asuntos celestiales, como en la naturaleza y en la materia (p. 36), de igual manera, quien es capaz de admirar la Belleza en estos elementos, puede contemplar el resplandor divino amándolo a su vez en todas las cosas.

Esta reivindicación neoplatónica, dio paso a la concepción romántica del amor. "La palabra 'romántico' fue introducida por poetas y filósofos alemanes hacia 1800 para indicar la visión del mundo que estaban creando" (Singer, 1999b, p. 318). Un mundo anclado en la tradición idealista que iba hacia el sentido de la naturaleza, allí el amor fue el sentimiento básico y el más grande que definió al hombre y la búsqueda de este sentimiento fue de gran interés para el mundo del siglo XIX y que pervive en la actualidad.

El amor romántico no se desligó totalmente de su pariente cortesano, ni mucho menos del amor cristiano con el elemento ágape de suma importancia en su conexión con Dios. Por el contrario, intentó integrar estas perspectivas. Aún establecía resonancias con el fine amore, por su concepción de amar en el sentido de bondad, en la que se encontraba tanto, el amor religioso como el terrenal y corpóreo.

En este sentido, la búsqueda de la Belleza y la Bondad aún, en la actualidad, conserva muchos de los aspectos del amor cortesano y del amor romántico, quizá para que el ser humano intente comprender la propia naturaleza del amor en el contexto presente y en su relación multilateral y multifactorial, ya que, "La sociedad de final del siglo XX vive todavía la disolución del romanticismo y no ha encontrado un camino muy claro para sustituir a sus formas de pensamiento que impregnan sin duda nuestra manera de pensar sobre el arte.” (Dufour, 1999, p. 226).

Además, "el pensamiento moderno sobre el amor a menudo ha perpetuado los conceptos del amor cortesano y romántico, y cómo también los ha sobrepasado" (Singer, 2006, p. 43); también ha considerado el aprecio y otorgamiento de valores, proyectos comunes, sentimientos que se dan entre seres humanos y sus propias creencias, en la vida en comunidad, en todas las relaciones humanas y con la naturaleza.

Una mirada reciente sobre el amor, y como diagnóstico de época, se encuentra en Zigmunt Bauman en "El amor líquido". El sociólogo, presenta las relaciones humanas en una nueva dinámica de consumo inmediato (Bauman, 2012, pos. 12\%), de frugalidad e 
inmediatez arrojadas a las lógicas del mercado y del avance tecnológico del presente siglo XXI.

Siguiendo a Bauman, las relaciones humanas encuentran, hoy en día, una proximidad virtual, no de "estar relacionado" sino de "estar conectado", lo que hace que, en primer lugar, las relaciones humanas sean más de tipo económico, cambiario y, en segundo lugar, en aquella fugacidad, cotidianidad y superficialidad relacional, se evidencia la fragilidad de vínculos humanos que permitan la construcción y conservación de dichos vínculos afectivos (pos. 41\%).

En palabras de Bauman:

El amor no encuentra su sentido en el ansia de cosas ya hechas, completas y terminadas, sino en el impulso a participar en la construcción de esas cosas. El amor está muy cercano a la trascendencia; es tan sólo otro nombre del impulso creativo, y por lo tanto, está cargado de riesgos, ya que toda creación ignora siempre cuál será su producto final. (2012, pos. $8 \%$ )

El amor no se dirige a lo bello sino, que se concibe y nace en él, "por eso el amante "busca y se esfuerza por encontrar la cosa bella en la cual pueda concebir"' (pos. 8\%), un amor sólido que se construya a partir del relacionamiento, de la robustez de los vínculos humanos y no de la fugacidad del contacto virtual, breve, pasajero y repentino.

En la misma lógica de la cultura del consumo, existe una perspectiva del amor, donde los productos están listos para su consumo al instante, "de lograr 'experiencia en el amor' como si se tratara de cualquier otra mercancía” (pos. 9\%) arriesgando los sentimientos y afectos de las personas involucradas.

\section{CONCLUSIÓN}

Este recorrido conceptual del amor ha permitido considerarlo en su dimensión histórica. Desde un espectro multidisciplinar, se ha entendido el enlace bidireccional que existe entre la razón y la emoción construida colectivamente en la gestión individual de las emociones y la forma de ser en sociedad; muestra ejemplar de esto es la canción popular, que recoge el sentimiento generalizado como un importante factor socioemocional comunitario que salta a la vista cuando se acepta por un gran número de coterráneos. La incorporación del autocontrol afectivo, su desarrollo colectivo y el intercambio, préstamo y adscripción interdisciplinarias del amor y las emociones en las Ciencias Sociales ha permitido un avance significativo en el desarrollo de su investigación y análisis como dato social.

Asumir la dimensión histórica del amor, requiere un recorrido desde la filosofía clásica griega, desde su concepción idealista, pasando por una mirada fisiológica natural propuesta por los poetas latinos Ovidio y Lucrecio, como hoja de ruta para el amor cristiano de naturaleza trascendente y espiritual. En contraste, la concepción medieval trovadoresca del amor tuvo en cuenta su naturaleza terrenal -híbrido entre el amor cortés y el romántico en su bondad, corporeidad y concupiscencia- como pedagogía de la contención caballeresca y masculina. Concepciones socio-históricas que en la actualidad se han criticado porque se analiza la fragilidad de los vínculos afectivos contenidos en dinámicas cambiarias y pasajeras junto a formas concretas de dominación y poder, por lo 
que la perspectiva feminista del amor ha dado un giro comprensivo como concepto histórico y práctica para la libertad y la emancipación de la humanidad en su máxima expresión. De tal suerte, es posible considerar el amor en su dimensión histórica de construcción social y afectiva, susceptible de cambio de orden social.

\section{REFERENCIAS BIBLIOGRÁFICAS}

Bauman Zigmunt. (2012). El amor líquido. Acerca de la fragilidad de los vínculos humanos. [versión EPUB] Ciudad de México: Fondo de Cultura Económica. Recuperado de https://www.bpdigital.cl/info/amor-liquido-acerca-de-lafragilidad-de-los-vinculos-humanos-00031374

Bolaños, Leidy, (2016). Estudio socio - histórico de las emociones y los sentimientos en las ciencias sociales del siglo XX. Revista de Estudios Sociales, No. 55, pp. 178 191. DOI: http://dx.doi.org/10.7440/res55.2016.12

Bosch, Esperanza, Ferrer, Victoria, Ferreiro, Virginia y Navarro, Capilla. (2013). La violencia contra las mujeres. El amor como coartada. Barcelona: Anthropos.

Burnley, David. (2012). Fine amor: su significado y contexto. Nueve ensayos sobre el amor y la cortesía en la Edad Media, compilado por Ana Basarte y editado por María Dumas, $(219$ - 251). Ciudad Autónoma de Buenos Aires, AR: Editorial de la Facultad de Filosofía y Letras de la Universidad de Buenos Aires. Recuperado de: http://repositorio.filo.uba.ar/bitstream/handle/filodigital/4178/Nueve\%20ensay os $\% 20$ sobre $\% 20$ el $\% 20$ amor $\% 20 y \% 201 \mathrm{l} \% 20$ cortesi $\%$ CC $\% 81 \mathrm{a} \% 20$ en $\% 20 \mathrm{la} \% 20 \mathrm{E}$ dad $\% 20$ Media_interactivo_0.pdf?sequence $=1$ \&isAllowed $=y$

Cabrelles Sagredo, María Soledad. (2007). Las emociones y la música. Revista de Folklore. Tomo 27b. Núm. 324, Recuperado de http://www.cervantesvirtual.com/ obravisor/las-emociones-y-la-musica/html/

Damasio, Antonio. (2000). Emoción y sentimiento. Sentir lo que sucede. Cuerpo y emoción en la fábrica de la consciencia, (49 - 98). Santiago de Chile: Andrés Bello. Traducción de: Pierre Jacomet.

D’ Ávila, Manuela. (2020). Por qué luchamos: un libro sobre amor y libertad. Ciudad Autónoma de Buenos Aires: Clacso; Ciudad de México: Siglo XXI Editores. Traducción de: María Paula Vasile.

Duby, Georges. (2012). El modelo cortés. Nueve ensayos sobre el amor y la cortesía en la Edad Media, compilado por Ana Basarte y editado por María Dumas, (11 - 34). Ciudad Autónoma de Buenos Aires, AR: Editorial de la Facultad de Filosofía y

Letras de la Universidad de Buenos Aires. Recuperado de: http://repositorio.filo. uba.ar/bitstream/handle/filodigital/4178/Nueve $\% 20$ ensayos $\% 20$ sobre $\% 20$ el $\% 2$ 0amor $\% 20 \mathrm{y} \% 201 \mathrm{a} \% 20$ cortesi $\%$ CC $\% 81 \mathrm{a} \% 20 \mathrm{en} \% 201 \mathrm{a} \% 20 \mathrm{Edad} \% 20 \mathrm{Media}$ _interac tivo_0.pdf?sequence $=1 \&$ isAllowed $=\mathrm{y}$

Dufour, Michèle. (1999). El amor cortesano y la canción trovadoresca. Ensayo de sociología de la música. Política y Sociedad, 32: pp. 207-230 Recuperado de https:/ / revistas.ucm.es/index.php/POSO/article/view/POSO9999330207A 
Ficino, Marsilio. (2001). De Amore o Comentario a «El Banquete» de Platón. Traducido por Rocío de la Villa Ardura. Madrid: Editorial Tecnos.

García, Adriana y Priscila Cedillo. (2011). Tras los pasos del amor: un recuento desde las ciencias sociales. Estudios Sociológicos, vol. 29, No. 86 pp. 551-602. Recuperado de https://www.jstor.org/stable/23043406

García Liendo, Javier, (2012). Las chicherías conducen al coliseo: José María Arguedas, tecnología y música popular. Revista de Crítica Literaria Latinoamericana, Año 38, No. 75, pp. 149-170, Centro de Estudios Literarios “Antonio Cornejo Polar"- CELACP, Recuperado de https://www.jstor.org/stable/23631267 Goleman, Daniel. (2010). Inteligencia emocional. Barcelona: Kairós.

Hauser, Arnold. (2012). El romanticismo de la caballería cortesana. Nueve ensayos sobre el amor y la cortesía en la Edad Media, compilado por Ana Basarte y editado por María Dumas, $(35$ - 82). Ciudad Autónoma de Buenos Aires, AR: Editorial de la Facultad de Filosofía y Letras de la Universidad de Buenos Aires. Recuperado de: http://repositorio.filo.uba.ar/bitstream/handle/filodigital/4178/Nueve $\% 20$ ensay os $\% 20$ sobre $\% 20$ el $\% 20$ amor $\% 20 y \% 201 \mathrm{l} \% 20$ cortesi $\%$ CC $\% 81 \mathrm{a} \% 20$ en $\% 201 \mathrm{l} \% 20 \mathrm{E}$ dad $\% 20$ Media_interactivo_0.pdf?sequence $=1$ \&is_Allowed $=\mathrm{y}$

Huizinga, Johan. (2012). La estilización del amor. Nueve ensayos sobre el amor y la cortesía en la Edad Media, compilado por Ana Basarte y editado por María Dumas, (425 - 441). Ciudad Autónoma de Buenos Aires, AR: Editorial de la Facultad de Filosofía y Letras de la Universidad de Buenos Aires. Recuperado de: http:/ / repositorio.filo.uba.ar/bitstream/handle/filodigital/4178/Nueve $\% 20$ ensay os $\% 20$ sobre $\% 20$ el $\% 20$ amor $\% 20 y \% 201 \mathrm{a} \% 20$ cortesi $\%$ CC $\% 81 \mathrm{a} \% 20$ en $\% 201 \mathrm{a} \% 20 \mathrm{E}$ dad $\% 20$ Media_interactivo_0.pdf?sequence $=1$ \&isAllowed $=\mathrm{y}$

Lagarde, Marcela. (2001). Claves feministas para la negociación en el amor. Managua: Puntos de encuentro.

Mita, Munesuke. (1996). Historia del anhelo de amor. En Psicología social del Japón moderno. $(89$ - 100). doi.org/10.2307/j.ctv3dnr4g.10

Platón. (2019). El Banquete. Islas Baleares: ES: Biblioteca digital abierta. Textos.info. https://www.textos.info/platon/el-banquete. (Documento original publicado 370 A.C.)

Saiz, Mónica. (2013). Amor romántico, amor patriarcal y violencia machista. Una aproximación crítica al pensamiento amoroso hegemónico de Occidente. Tesis de grado Máster universitario en estudios feministas. Instituto de investigaciones feministas. Universidad Complutense de Madrid, Madrid, España. Recuperado de https:// www.ucm.es/data/cont/docs/329-2013-12-17-TFM\%20M\%C3\%B3nica $\% 20$ Saiz. pdf

Singer, Irving. (1999a). De Platón a Lutero. La naturaleza del amor (Vol. 1). Ciudad de México: Siglo XXI.

(1999b). Cortesano y romántico. La naturaleza del amor (Vol. 2). Ciudad de México: Siglo XXI. 
. (2006). El mundo moderno. La naturaleza del amor (Vol. 3). Ciudad de México: Siglo XXI.

Torregrosa, José. (1984). Emociones, sentimientos y estructura social. Estudios básicos de pscicología social, (185 - 199). Barcelona: Hora.

\section{CITAR COMO:}

Forero Perdomo, N. (2021). Consideraciones interpretativas sobre el amor dentro del mundo social. Puriq, 3(4), 527-540. https://doi.org/10.37073/puriq.3.4.227 